Article

\title{
Experimental Evidence of PID Effect on CIGS Photovoltaic Modules
}

\author{
Sofiane Boulhidja ${ }^{1}$, Adel Mellit ${ }^{1,2}$, Sebastian Voswinckel ${ }^{3}$, Vanni Lughi ${ }^{4}$, Alessandro Ciocia ${ }^{5}$, \\ Filippo Spertino 5 (D) and Alessandro Massi Pavan ${ }^{4, *}$ \\ 1 Renewable Energy Laboratory, Faculty of Sciences and Technology, Jijel University, Ouled-Aissa P.O. Box. 98, \\ Jijel 18000, Algeria; s.boulhidja@gmail.com (S.B.); adelmellit2013@gmail.com (A.M.) \\ 2 The Abdus Salam International Centre for Theoretical Physics (ICTP), Strada Costiera, 11, 34151 Trieste, Italy \\ 3 RET-Institute for Renewable Energy Technology, University of Applied Sciences Nordhausen Weinberghof \\ 4,99734 Nordhausen, Germany; voswinckel@fh-nordhausen.de \\ 4 Department of Engineering and Architecture, University of Trieste, Via A. Valerio, 6/A, 34127 Trieste, Italy; \\ vlughi@units.it \\ 5 Department of Energy Engineering “Galileo Ferraris”, Polytechnic of Turin, Corso Duca Degli Abruzzi, 24, \\ 10129 Turin, Italy; alessandro.ciocia@polito.it (A.C.); filippo.spertino@polito.it (F.S.) \\ * Correspondence: apavan@units.it
}

Received: 13 December 2019; Accepted: 20 January 2020; Published: 22 January 2020

check for updates

\begin{abstract}
As well known, potential induced degradation (PID) strongly decreases the performance of photovoltaic (PV) strings made of several crystalline silicon modules in hot and wet climates. In this paper, PID tests have been performed on commercial copper indium gallium selenide (CIGS) modules to investigate if this degradation may be remarkable also for CIGS technology. The tests have been conducted inside an environmental chamber where the temperature has been set to $85{ }^{\circ} \mathrm{C}$ and the relative humidity to $85 \%$. A negative potential of $1000 \mathrm{~V}$ has been applied to the PV modules in different configurations. The results demonstrate that there is a degradation affecting the maximum power point and the fill factor of the current-voltage $(I-V)$ curves. In fact, the measurement of the $I-V$ curves at standard test condition show that all the parameters of the PV modules are influenced. This reveals that CIGS modules suffer PID under high negative voltage: this degradation occurs by different mechanisms, such as shunting, observed only in electroluminescence images of modules tested with negative bias. After the stress test, PID is partially recovered by applying a positive voltage of $1000 \mathrm{~V}$ and measuring the performance recovery of the degraded modules. The leakage currents flowing during the PID test in the chamber are measured with both positive and negative voltages; this analysis indicates a correlation between leakage current and power losses in case of negative potential.
\end{abstract}

Keywords: photovoltaic modules; CIGS cells; bias; potential induced degradation; leakage current

\section{Introduction}

Thin film photovoltaic (PV) modules in copper indium gallium diselenide (CIGS) are an excellent alternative to crystalline silicon (c-Si) modules in terms of cost and efficiency. For these characteristics, they have been consistently used worldwide in the past decade. PV modules are usually series-connected in PV strings in order to increase the system voltage; in Europe, the maximum direct current (DC) voltage currently allowed by the regulations is $1500 \mathrm{~V}$ for safety. When a point of the DC circuit of the PV system is grounded, a high electric potential difference between the solar cells and the frame of the modules can drive a mechanism known as potential induced degradation (PID). PID occurs in both crystalline silicon and thin film PV modules and can considerably compromise the performance of a PV system, especially if this operates at a high DC voltage [1]. PID can provoke catastrophic 
consequences in the operation of a PV system: in some cases, CIGS modules have essentially stopped functioning after bias application [2]. Thus, it is important to understand how the PID phenomenon works and how to prevent it.

The PID effect has received considerable attention; therefore, many researches were carried out on PID degradation occurring in crystalline silicon PV modules, which represent the most installed PV technology over the world. Hacke et al. [3] reported that a sample of polycrystalline silicon (p-Si) modules inside an environmental chamber, with a temperature of $85^{\circ} \mathrm{C}$ and a relative humidity of $85 \%$ under a negative voltage of $600 \mathrm{~V}$, exhibited a decay of $80 \%$ in maximum power after a short time of the test. Nagel et al. [4] reported that, after maintaining p-Si modules in the field under a negative voltage of $1000 \mathrm{~V}$, they showed a power loss more than $50 \%$ within 25 weeks. Furthermore, Islam et al. [5] investigated the real PID of c-Si modules installed in a power plant: they reported an on-site power degradation of $46.5 \%$ after a duration of a negative voltage stress for nearly 11 years. Some authors reported a power loss range from $10 \%$ to $90 \%$ for various c-Si modules (including mono and poly-crystalline cells) after PID tests inside chamber [6]. PID has been also tested on monocrystalline modules: Oh et al. reported that p-base mono-crystalline silicon cells lost approximately $50 \%$ of their initial power at $-600 \mathrm{~V}$ after just $44 \mathrm{~h}$ [7]. Goranti et al. [8] investigated that the remaining power of mono-crystalline modules stressed at $85^{\circ} \mathrm{C}$ dry heat, with negative voltage of $600 \mathrm{~V}$ was about $15 \%$ compared to the pre-test power [8], as the c-Si modules are affected by PID; some authors reported that coating a $\mathrm{TiO}_{2}$ thin film on the cover glass of modules can prevent them from PID [9].

The PID in thin film modules is mostly attributed to the diffusion of $\mathrm{Na}+$ ions originating from the module glasses, via different mechanisms depending on the presence or absence of moisture, and is often manifested through delamination or corrosion of the transparent conducting oxide (TCO) layer of the module. This can cause a drastic reduction of the module performance [10-13]; Fjällström et al. [14] reported that PID effect can drive the efficiency of CIGS cells to drop to about zero.

As well known, the PID effect highly depends on the environmental conditions, especially temperature and relative humidity. If a PV module is subject to high potential (with the proper sign) under these conditions, a drastic degradation of the module performance can happen: the degradation seems to be correlated with the leakage current flowing between the module frame, usually grounded, and the active parts of the solar cells; this current crosses the encapsulant material of the module. It has been reported that the leakage current flowing through the glass and the encapsulant leads to an accumulation of trapped negative charges on the active layer [15]. There are different pathways for the leakage current to flow between the frame of the module and the solar cells. The pathway from the active layer to the frame through the front glass which has a high surface conductivity is the most dominant during the PID effect $[16,17]$. The low resistivity is mainly due to the encapsulant material: the soda-lime glass used in thin-film PV modules can be the source of sodium ions that, located at the front glass surface, might lead to a loss of the efficiency [18-20]. Even though the PID mechanism is not yet well understood, the sodium ions that migrate from the glass to the TCO seem to be one of the main reasons for the degradation [14]. The migration of the sodium ions causes a cell shunting that leads to a reduction of the module efficiency together with a deterioration of the main electrical characteristics [14,21]. It has also been demonstrated that PID degraded modules can recover from their condition by applying a positive bias [22]. The PID stress is related to the materials used to fabricate the modules and can be suppressed by using a sodium-free front cover glass, Yamaguchi et al. have reported that CIGS modules can be prevented from PID by using an ionomer encapsulant [16].

The purpose of the present work is to provide initial reference results about PID effect on commercial CIGS modules by a sample from a manufacturer. Manufacturing processes are constantly evolving; thus, the future modules will be able to withstand harsher environmental conditions without manifesting remarkable PID worsening, with obvious advantages in terms of reliability and life of the PV system.

In this work, tests have been performed on some commercial CIGS modules working in an environmental chamber and connected to both a negative and a positive high voltage. The current 
voltage $(I-V)$ curves and the main electrical parameters have been collected and investigated. Electroluminescence imaging has been used in order to analyse the non-visible degradation process. The leakage current flowing between the ground and the cells' active layer has also been measured. A final "recovery" test has been performed in order to bring the PV modules back to their initial conditions. The adopted methodology and the results will be used as a reference for researchers that will compare them with new results obtained on CIGS modules from different manufacturers.

\section{Diagnostics Techniques for PID Detection}

The $I-V$ curve measurement and the electroluminescence (EL) test are two complementary diagnostics techniques. The $I-V$ curve measurement allows a quantitative evaluation of the PV module performance, while the EL gives a qualitative state of health, with details about the causes of the failures.

\subsection{Description of Diagnostics Techniques for Defects Detection}

Regarding the determination of $I-V$ curves, the dynamic methods consist of the use of capacitive or electronic loads [23], with an adequate and calibrated measurement system [24]. A typical scheme of the measurement system with capacitive load is shown in Figure 1; voltage, current, irradiance, and ambient temperature are detected simultaneously (the irradiance sensor and the thermometer for ambient temperature are not represented).

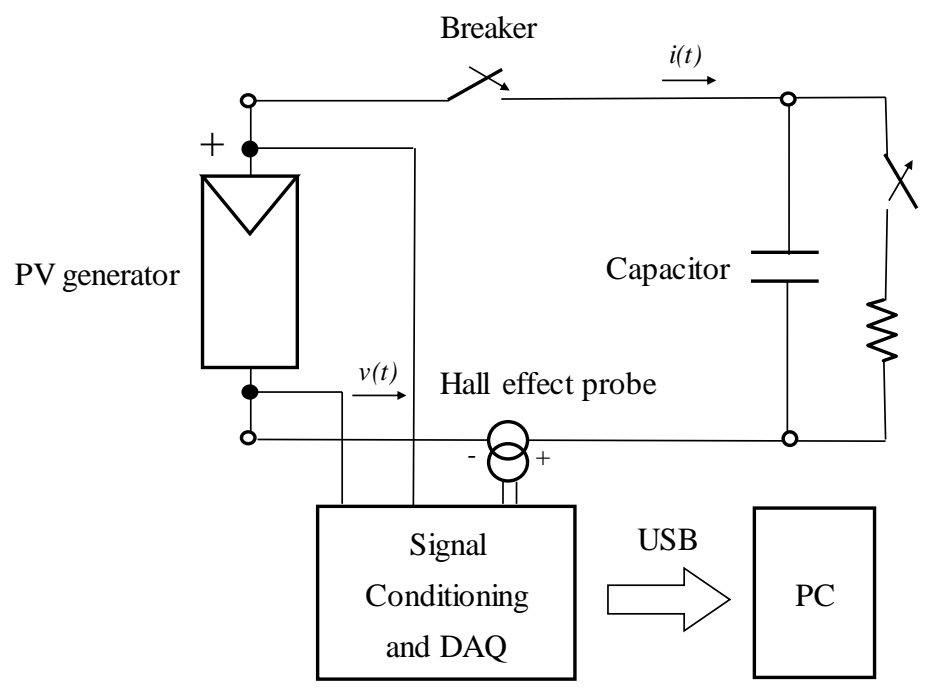

Figure 1. Measurement scheme for the $I-V$ characterization of a photovoltaic (PV) generator by capacitive load.

Thanks to the capacitive load [25], the scan of the entire $I-V$ curve can be easily performed at any level (module, string and array) up to hundreds of kilowatts. The elaboration of the $I-V$ curve points permits to obtain all the electrical parameters, in particular the actual power output and the performance of the module. The only limitation of the $I-V$ curve characterization is that it cannot easily provide information about the causes of the parameter deviations. In order to define the causes of underperformance, electroluminescence tests are even more used, thanks to higher accuracy and much lower costs than in the past [26].

The analysis of the EL images permits to justify the performance deviation with mechanical/chemical defects. The EL test starts with a forward bias of the PV module, obtained thanks to an appropriate DC power supply (Figure 2), in a totally shaded condition (e.g., in a dark room of a laboratory or on-field with low irradiance). The PV cells work like light emitting diodes (LEDs), in which their semiconductor materials have emission spectra in the infrared (IR) region of the 
electromagnetic spectrum and not in the visible region [27]. The image, captured by the sensor, is post processed to permit the identification of the defects.

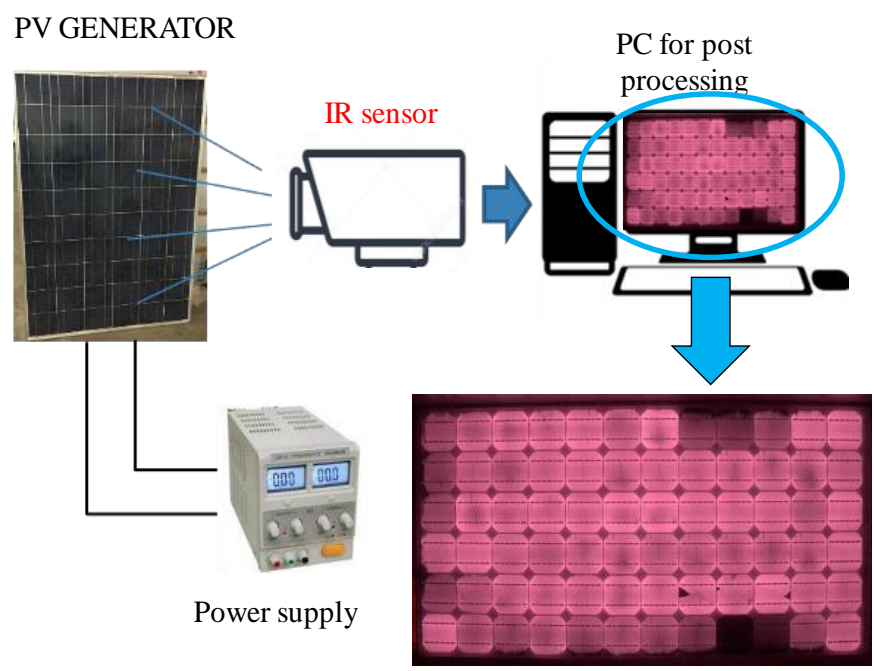

Figure 2. Scheme for the electroluminescence (EL) test of a PV module.

In case of c-Si silicon modules, the IR emission is in the range 900-1300 $\mathrm{nm}$, and the peak, corresponding to the bandgap, is at $1150 \mathrm{~nm}$. This emission can be partially detected by cheap silicon sensors, i.e., silicon charge-coupled device (CCD) or CMOS. On the other hand, the use of an expensive sensitive camera equipped with indium gallium arsenide (InGaAs) photodiodes is necessary for CIGS [28]. In case of CIGS generators, the emission curve can reach a wavelength of $1400 \mathrm{~nm}$ and it is better matched by the absorption curve of an InGaAs detector.

\subsection{Detection of PID}

The PID is easily identifiable in images obtained by EL. As an example, Figure 3 shows the EL image of c-Si modules installed on a rooftop. The working cells emit infrared radiation and are bright and homogenous (an example of two well working cells is highlighted by a white circle). On the contrary, the inactive parts of cells are dark. In the module in the centre of this Figure 3 , there are 60 cells, each one with a size of $15.6 \times 15.6 \mathrm{~cm}$. About 40 cells are well working, while the rest (20) are defective.

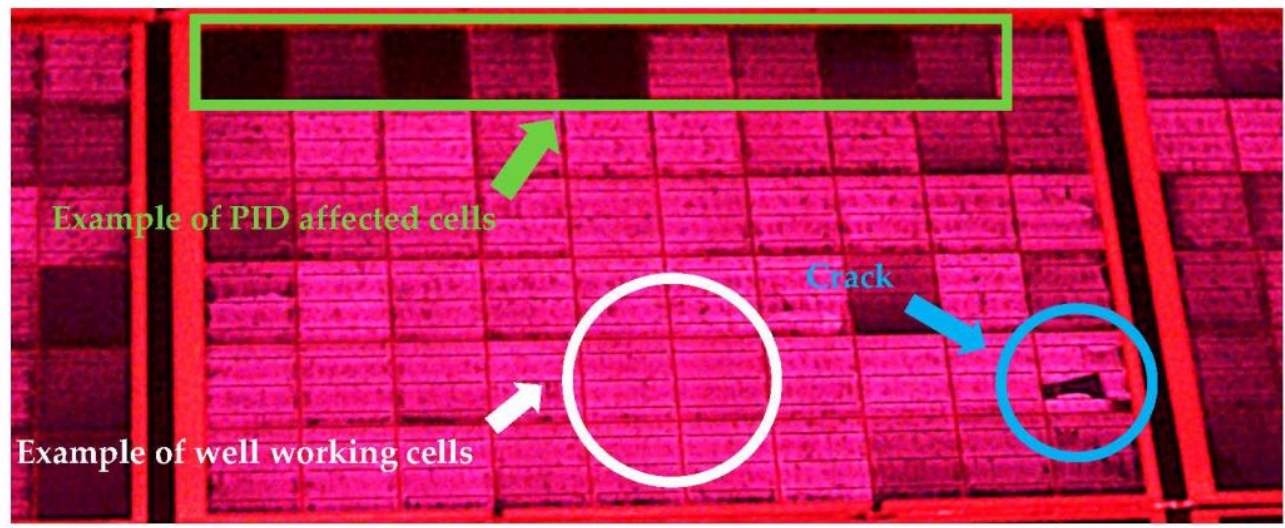

Figure 3. EL image of a c-Si module affected by potential induced degradation (PID) and cracks.

PID affected cells are black or partially dark with an inhomogeneous luminescence. Generally, they are along the frame, where the paths of the PID current have a lower resistance. However, PID affected cells can be present also in the centre of the modules. The worst PID cells (totally black/inactive) 
are highlighted by a green rectangle in the top of the same figure. The other cells are in an intermediate situation, in which they are partially working. In order to make a comparison between PID and other defects, the module shown in Figure 3 is affected by both PID and cracks. Actually, this figure refers to modules installed on a rooftop, and cracks appear due to the walking on the PV modules mainly during maintenance [29]. The cracked cell is highlighted by a blue circle in Figure 3; the crack is easily identifiable because the black/inactive area has well-defined edges. Another aspect which supports in the identification of PID is the distribution of inactive cells along the PV strings. As well described in the next chapter, the PID occurs when a high negative voltage is applied between the cells (n-type layer in contact with the glass) and the metallic frame. Thus, supposing a floating voltage of the PV generator (in case of transformerless DC/AC converters), the most affected modules will be the ones at the end of the string (near the negative pole of the string), where there is a negative potential with respect to the ground (Figure 4).

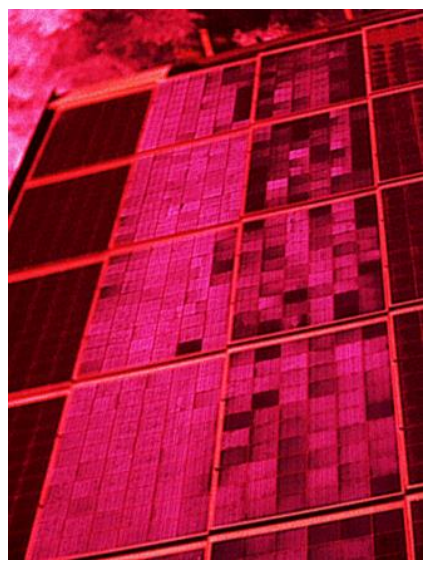

(a)

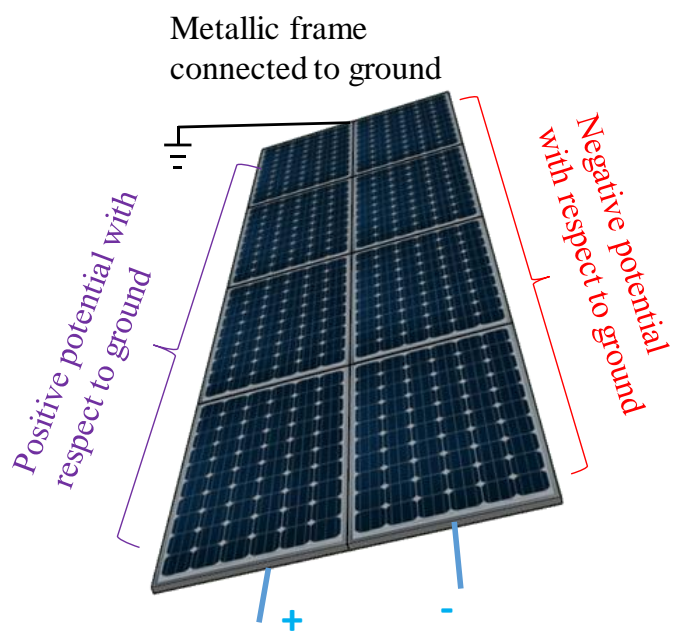

Floating poles of the PV generator

(b)

Figure 4. (a) EL image of a PV string of c-Si cells affected by PID; (b) identification of modules affected by a negative potential between the PV cells and the metallic frame connected to ground.

\section{Experimental Setup}

\subsection{Degradation}

Figure 5 represents the sketch of the PID test in the climatic chamber. In the present work, a commercial device made by ATT Angelantoni Test technologies is used. It has a test volume of $11 \mathrm{~m}^{3}$, the temperature range is from -60 to $+100{ }^{\circ} \mathrm{C}$ and the relative humidity can be controlled between $10 \%$ and $95 \%$. The tests have been performed in three different configurations, as follows. In the first configuration, the positive terminal of the DC power supply has been connected to the front surface of the PV modules (a metallic foil is placed on the surface to equalize the electric potential), while the negative terminal with high voltage of $1000 \mathrm{~V}$ has been connected to the PV terminals in short circuit.

In the second one, the only difference is that the positive terminal of the DC power supply has been connected to the back surface (by the same metallic foil). In the third one, the positive terminal of the DC power supply has been connected to the frame of the PV modules. The CIGS modules under study are four. the p-type (CIGS) is rear-side and n-type (CdS) is front-side. The frames of three modules, subject to artificial PID, have been grounded and one module without bias has been used as a reference, remaining at beginning of life. 


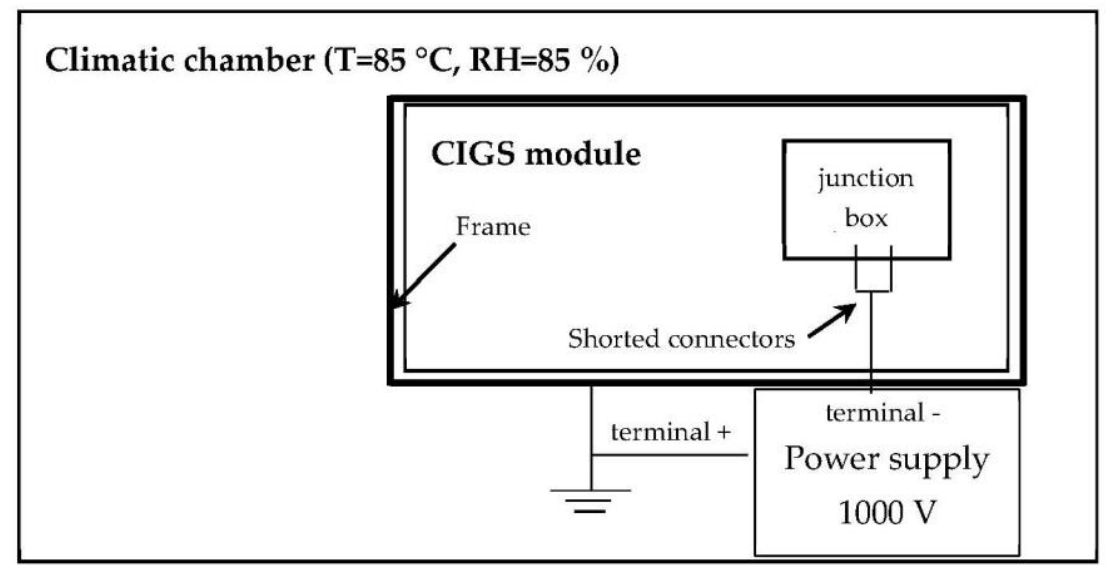

Figure 5. PID setup with grounded frame, the PV connectors are shorted and connected to the negative potential of the power supply.

The specifications of these PV modules (Bosch Solar) at STC are: maximum power $P_{\max }=74.6 \mathrm{~W}$, open circuit voltage $V_{\mathrm{oc}}=71.7 \mathrm{~V}$, short circuit current $I_{\mathrm{sc}}=1.47 \mathrm{~A}$, voltage at maximum power point $V_{\mathrm{mpp}}=56.5 \mathrm{~V}$, and current at maximum power point $I_{\mathrm{mpp}}=1.32 \mathrm{~A}$. The power tolerance is $\pm 5 \%$.

Firstly, the PV modules have been placed in an environmental chamber, where the temperature has been maintained at a constant value of $85{ }^{\circ} \mathrm{C}$, and the relative humidity has been set to $85 \%$. After the desired conditions have been reached, a negative voltage bias $(1000 \mathrm{~V})$ has been applied to the shorted leads of the modules, while their frames have been grounded. After a first cycle of about $20 \mathrm{~h}$, the modules have been removed from the chamber and characterized using a flash tester, recording the $I-V$ curves as well as calculating the electrical parameters (including short circuit current $I_{\mathrm{sc}}$ and $V_{\mathrm{oc}}$ ). The flash tests have been performed at the standard test conditions (STC): irradiance of $1000 \mathrm{~W} / \mathrm{m}^{2}$, corresponding to air mass 1.5 , and cell temperature of $25^{\circ} \mathrm{C}$. STC conditions have been obtained in a dark room with temperature control and an artificial light. A pulsed solar simulator (PSS 8 from Berger) has been used; it consists of a Xenon flash tube; resistive loads are used to trace the $I-V$ curves. According to IEC 60904-9 [30], the simulated spectrum AM 1.5 G, the spatial uniformity and the temporal stability outperform A class [31]. The measurements are acquired by a data acquisition system (12 bit-resolution) with typical uncertainty $<0.5 \%$ for both voltage and current and $1 \%$ for power.

Afterwards, the modules have been placed again in the chamber to continue the PID test. The flash test measurements have been frequently repeated after about $20 \mathrm{~h}$ until the end of the test with a total duration of $120 \mathrm{~h}$.

The leakage current flowing between the module connectors and the frame contact has been continuously recorded during the PID test in order to find a correlation between the leakage current and the degradation. Moreover, to visualize the affected regions, electroluminescence images of the modules have been acquired before and after the PID test.

\subsection{Recovery}

After the PID stress, the modules have been biased with a positive voltage of $+1000 \mathrm{~V}$, in order to investigate the capability of performance recovery. The test has been performed in the climatic chamber with the same temperature and relative humidity $\left(85^{\circ} \mathrm{C} / 85 \% \mathrm{RH}\right)$, with the same combinations of bias and connections used in the previous test. A test similar to PID has been performed on light soaked modules using the same configuration as the first test, the light soaking setup has been performed before the chamber testing, using a steady-state sun simulator for $2 \mathrm{~h}$. In addition to the stressed modules, other two new modules have been biased with a positive voltage of $1000 \mathrm{~V}$ : they are used as a reference for the recovery test to compare the effect of voltage polarization on the performance. All the PV modules have been tested for a total duration of $120 \mathrm{~h}$, and removed frequently after about $20 \mathrm{~h}$ of stress for the measurement of the $I-V$ curves with the flash tester. Furthermore, the leakage 
current has been logged continuously for all the modules and the EL images have been taken before and after the tests inside the chamber.

\section{Results and Discussion}

\subsection{Degradation}

All the modules have been characterised at STC conditions. Figure 6 shows the $I-V$ curves of three modules tested inside the climatic chamber with both negative (front contact of the first test) and positive (front contact of the second test) bias of $1000 \mathrm{~V}$, and an unbiased module used as a reference. As shown in Figure 6, both the positive biased module and the unbiased module show similar behaviour with slight degradation, mainly due to the expected effect of high temperature and relative humidity inside the environmental chamber. On the contrary, the negative bias drives the sample to degrade significantly at the end of the test compared to the other samples. These results reveal that the high negative voltage induces PID degradation, in the CIGS modules under tests, with a remarkable power loss similar to the power losses in the crystalline silicon modules from different manufacturers. It is worth noting that the PID affected modules have not shown any visible discoloration.

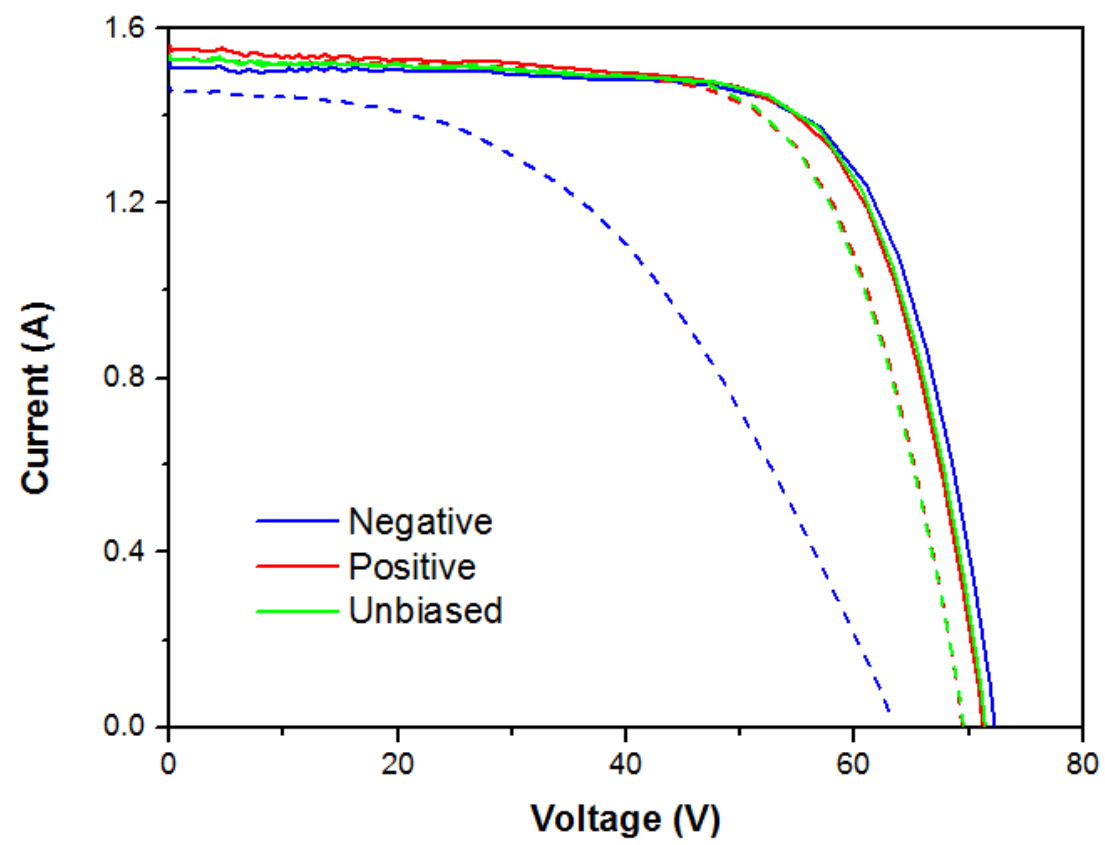

Figure 6. $I-V$ curves of the three modules before (solid lines) and after (dotted lines) the tests in chamber.

The changes in electrical parameters of the modules during the tests with positive bias have been investigated: these changes result linked with the applied bias and environmental conditions inside the climatic chamber. Figure 7 shows the normalized values (with respect to the initial values) of the maximum power, $P_{\max }$, and the Fill Factor $F F=P_{\max } /\left(I_{\mathrm{sc}} \cdot V_{\mathrm{oc}}\right)$ as a function of stress time inside the climatic chamber. Here, the connections are different: positive bias $(1000 \mathrm{~V})$ applied to the front contact, to the back contact, to the frame, and unbiased module. 


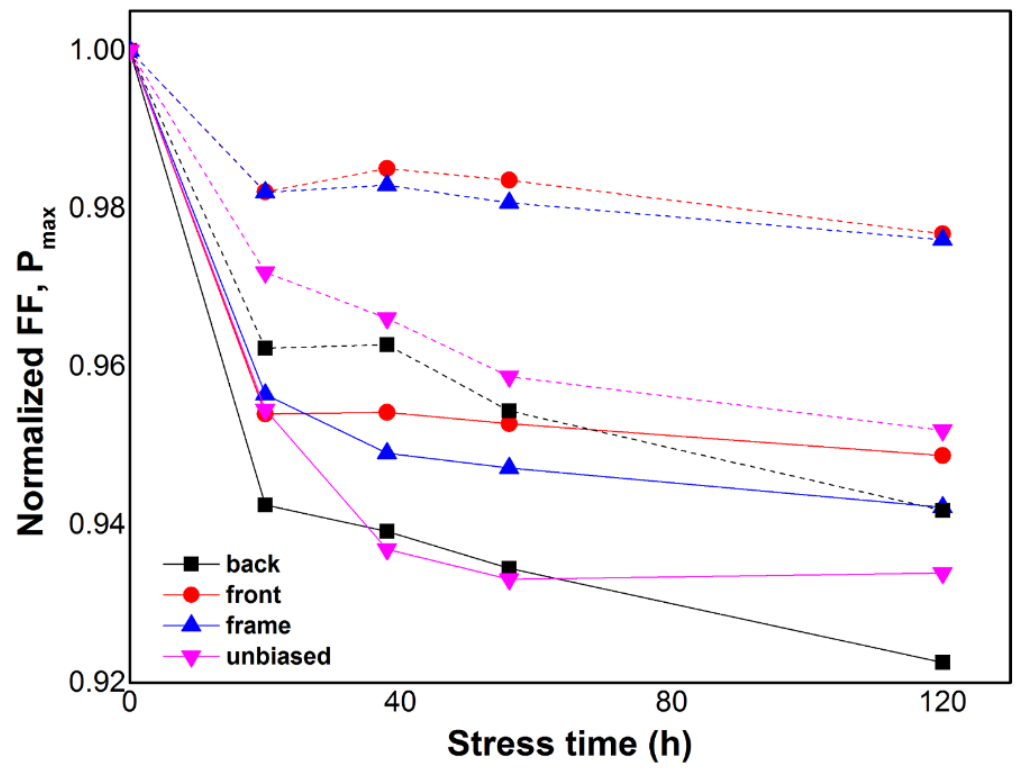

Figure 7. Normalized maximum power (solid lines) and fill factor (dashed lines) of the tested modules as a function of time with positive voltage.

Before the PID tests, for all the modules (four) the measured maximum powers have been very similar $\left(P_{\max , \mathrm{r}}=77 \mathrm{~W}\right)$ and the corresponding fill factor has been $F F_{\mathrm{r}}=68 \%$, where the deviations are smaller than the uncertainty of the data acquisition system $( \pm 0.5 \%$ for both voltage and current, $\pm 1 \%$ for power). In order to easily show the deviations, normalized values are used: they are calculated as the ratio between the measured value after the test and the initial value. In the first hours inside the chamber, all the modules have exhibited a noticeable degradation of $P_{\max }$ and $F F$. Normalized $P_{\max }$ has been reduced: the back contact and unbiased modules have rapidly highlighted a similar behaviour and decreased slowly down to 0.92 and 0.93 respectively, while the front and frame contacts have been degraded to 0.95 at the end of the test. Fill factor has shown a decrease to 0.98 with a similar behaviour for the front and frame contacts, while the $F F$ for the back contact and unbiased modules has been degraded to 0.95 . These results reveal that testing under harsh enviromental conditions and high voltage can have a slight effect on the modules performance, the damp-heat conditions $\left(85^{\circ} \mathrm{C} / 85 \% \mathrm{RH}\right)$ lead to losses in the FF of CIGS cells. The decrease of the FF can be associated with an increase of series resistance, that is mainly caused by an enhancement in the resistivity of the transparent conductive oxide (TCO) layers. In $[32,33]$, it is confirmed that this is the cause of performance losses of PV modules in damp-heat conditions.

The PV modules with front and frame contact connections have shown less degradation, because the forward bias has maintained the PV modules at a stable condition; on the contrary, the unbiased module has shown an higher performance degradation [34]. Taking into account the measurement uncertainties (typical amount of $\pm 1 \%$ for the current and the voltage values) arising during the flash testing, the evolution of the parameters can be attributed to metastabilities changes.

Figure 8 shows the time evolution of the normalized parameters of the five modules under test with negative voltage of $1000 \mathrm{~V}$. The results demonstrate that the PID effect is similar in the case of the tests with the back and the front contacts. After $120 \mathrm{~h}$, even if $V_{\mathrm{oc}}$ and $I_{\mathrm{sc}}$ have remained constant, both the maximum power and the fill factor have substantially decreased with the stress time. Really, as shown in Figure 8, the average of $P_{\max }$ and $F F$ has been decreased by $35 \%$ at the end of the test. These degradations lead to a significant reduction in the efficiency of the modules and in their capability to produce energy. In the case of light soaked modules, $P_{\max }$ and $F F$ have decreased similarly to non-light soaked modules, with some changes arising during the test because of the metastabilities occurring with light soaking presenting in slight increase in the first hours and some unexpected degradation 
during the test. The FF of light soaked modules has shown less degradation at the end of the PID test comparing to no light-soaked modules.
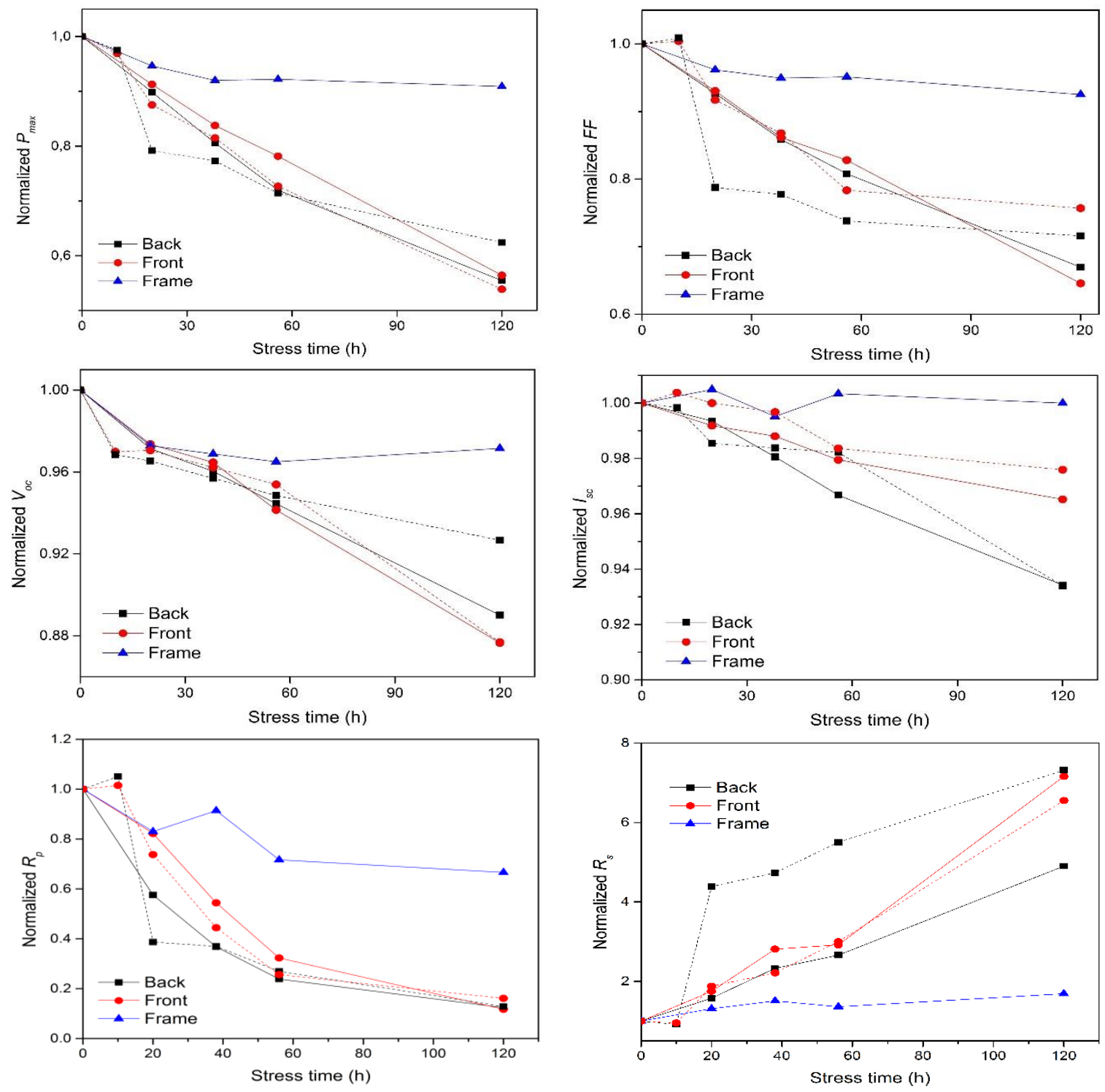

Figure 8. Parameters of the modules with different contacts as a function of time. The dotted lines refer to the light soaked modules.

The exposure to $120 \mathrm{~h}$ of stress in the chamber has caused an increase of $\approx 12 \%$ of $V_{\text {oc }}$ in the modules with both front and back contacts, respectively. On the contrary, the frame contact module has decreased only by $3 \%$. The $I_{\mathrm{sc}}$ exhibits slight degradation, it has dropped by $3 \%$ and $6 \%$ for the front and back contact tests, respectively. The degradation can be affected also by other parameters, however, the data reveal that the degradation of the modules is associated to a large decrease in the shunt resistance $R_{\mathrm{p}}$ (about $80 \%$ ) and to an even more dramatic increase of the series resistance $\mathrm{R}_{\mathrm{s}}$ (by a factor of about 7), which affect the fill factor. It is evident that all electrical parameters of the frame contact module seem to be slightly changed after the PID test.

It is worth noting that the evolution of the electrical parameters is only marginally influenced by the preliminary light soaking. Conversely, a small increase of the fill factor and of the short circuit current is observed during the first hours. This is due to the metastabilities of the PV modules in CIGS $[35,36]$ and does not prevent the degradation of the modules because of the strong PID effect. 
Another important indication is that the positive bias does not influence much the performance of the modules, while the negative bias leads to an extensive degradation of their performance

The EL images of the four modules before and after the PID stress are displayed in Figure 9. As seen in the previous results of Figure 8, the negative bias drives for obvious degradation of electrical parameters, while the PV modules have not shown any visible degradation nor any corrosion in the TCO layer. The EL images remarkably prove wide darkening areas, this consideration is applied to the front contact (Figure 9a) as well as for the back contact (Figure 9b), where a huge darkening area can be observed in the middle of the module, which is corresponding to the shunt resistance degradation highlighted in Figure 8, while the test with the frame shows a small degradation around the perimeter. Obviously, there are no changes in the EL images of the fourth module (Figure 9d) that was not stressed and has been kept new as a reference module. On the other hand, in case of crystalline silicon modules affected by PID, the inactive cells belong to the modules subject to a more negative potential (close to the negative pole of the PV string) and are located along the borders near the frame.
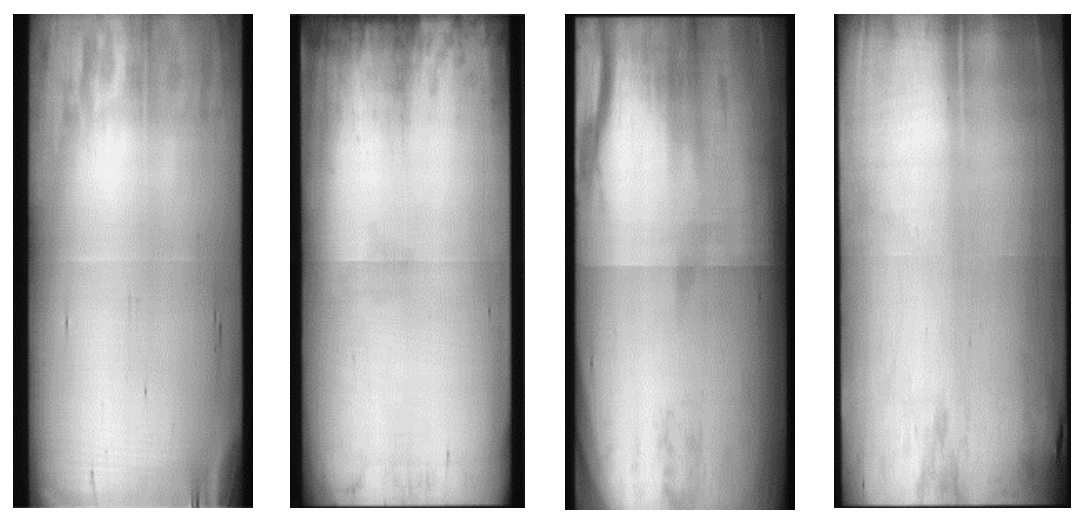

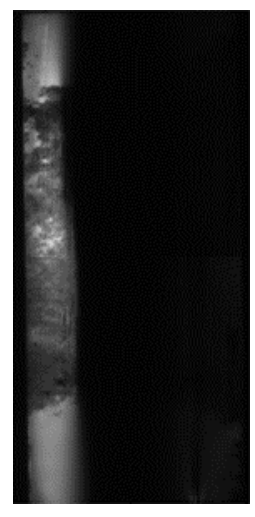

(a)

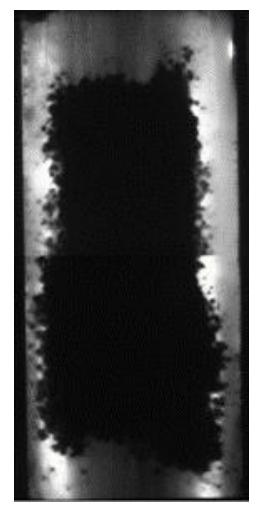

(b)

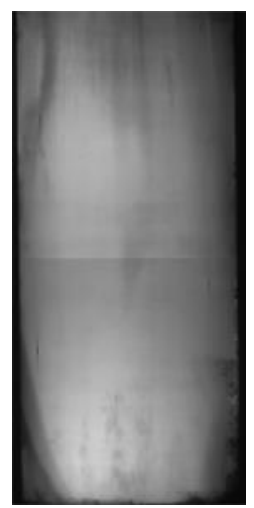

(c)

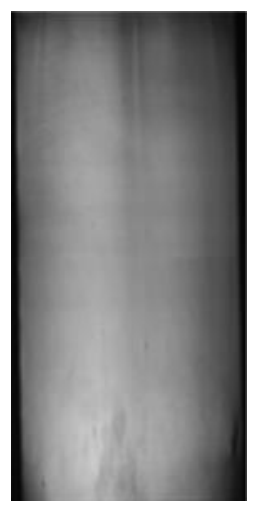

(d)

Figure 9. EL images of the tested modules at $85^{\circ} \mathrm{C}$ and $85 \% \mathrm{RH}$, before (upper images) and after (lower images) the test for different contacts: (a) front, (b) back, (c) frame, and (d) unbiased.

The dark regions shown in the EL images, which are due to the shunting mechanisms occurring in the middle or near the edge of the modules because of the contact used to apply the voltage for the PID test. Therefore, for both front and back contacts, the current is concentrating in the middle of modules, whereas for frame contact the current is concentrating at the edge and affects less the module. This witnesses the extensive degradation of the modules together with the big changes observed for the electrical parameters.

The shunting mechanisms are mainly associated with the migration of the sodium ions $\left(\mathrm{Na}^{+}\right)$ from the cover glass toward the active part of the solar cells and the CdS layer. In addition, the sodium 
ions are also located in the CIGS/Mo interface or in the back of modules and can also follow this path to migrate and accumulate in the active cell. The sodium ions move because of the applied voltage, and this happens more when the bias is negative $[7,11]$. This movement can be associated with a redistribution of charges which leads to an enhancement of the recombination effect in the depletion zone. This phenomenon, which might be the cause of the shunt resistance drop, certainly reduces the open circuit voltage and the short circuit current with a consequent loss of power.

On the other hand, the dark areas shown in the EL images are also related to the obvious increase of the series resistance shown in Figure 8, the luminescence emission is variable due to the sheet resistance of the TCO and the Mo back layer [37]. The dark areas represent parts of a module where there is a poor or even a zero current flow. The increased value of the series resistance is the cause of the degradation of the fill factor.

\subsection{Recovery}

As shown in the previous section, the critical environmental conditions together with the application of a high negative bias lead to a significant degradation of the main parameters of the modules and to a consistent efficiency loss. As the negative bias has been recognized to be the main cause of the degradation occurred during the test, a second test has been performed in order to show how an opposite bias could contribute to recover the modules.

Table 1 shows the changes in the electrical parameters of the degraded modules (front, back, and frame contacts) after the first PID test. The PV modules have been placed in the environmental chamber at a temperature of $85{ }^{\circ} \mathrm{C}$ and a relative humidity of $85 \%$; a positive voltage of $1000 \mathrm{~V}$ has been applied for $120 \mathrm{~h}$.

Table 1. Normalized electrical parameters to pre-PID test value of modules, before and after the recovery test.

\begin{tabular}{ccccccc}
\hline Parameter & \multicolumn{3}{c}{$\begin{array}{c}\text { After the PID Test (Before } \\
\text { Recovery) }\end{array}$} & \multicolumn{3}{c}{ After the Recovery Test } \\
\hline & Back & Front & Frame & Back & Front & Frame \\
$\boldsymbol{P}_{\text {max }}[\%]$ & 0.55 & 0.56 & 0.91 & 0.64 & 0.75 & 0.89 \\
$\boldsymbol{F F}[\%]$ & 0.66 & 0.64 & 0.92 & 0.68 & 0.75 & 0.92 \\
$\boldsymbol{I}_{\text {sc }}[\%]$ & 0.93 & 0.96 & 1.00 & 0.97 & 0.99 & 1.00 \\
$\boldsymbol{V}_{\mathbf{~ o c}}[\%]$ & 0.89 & 0.87 & 0.97 & 0.96 & 0.96 & 0.96 \\
\hline
\end{tabular}

All the electrical parameters have improved after the test showing that applying a positive voltage gives the capability to recover partially the performance of the degraded modules. In particular, the effect of the recovery test is particularly more beneficial in the case of the bias applied to the front contact. For this configuration and for the back connection, at the end of the test the short circuit current and the open circuit voltage have recovered to a high degree. Conversely, the maximum power and the fill factor are both only the $75 \%$ of the initial values. The case of frame connection does not exhibit an improvement of performance after recovery.

Figure 10 shows the EL images of the modules after the recovery test. The dark regions have become more luminescent confirming that the shunting mechanisms, occurred in the modules during the PID test, have been partially recovered. This is because the positive bias reverses the migration paths of the sodium ions which are attracted and accumulated in the active cells after the PID test. 


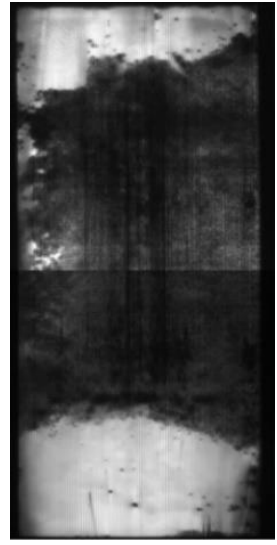

(a)

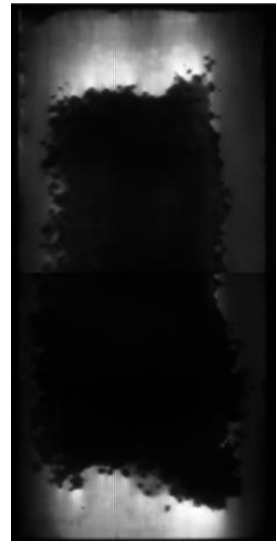

(b)

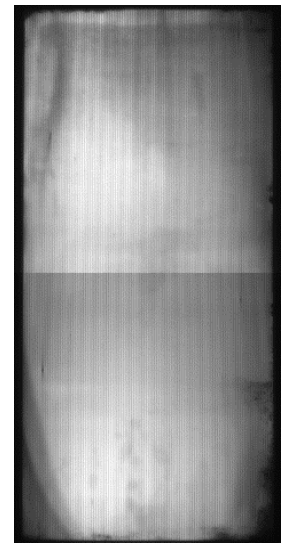

(c)

Figure 10. Electroluminescence images of the PV modules after the recovery test: (a) back contact, (b) front contact, and (c) frame contact.

\subsection{Leakage Current Analysis}

A third analysis has been carried out on the leakage current flowing during the PID test (voltage $1000 \mathrm{~V}$, temperature $85^{\circ} \mathrm{C}$, relative humidity $85 \%$ ) which increases the surface conductivity of the modules. The leakage currents known as the transferred charges from the active layer to the frame, are plotted in Figure 11; these leakage currents are related to the PID effect. The highest current has been observed for the front contact configuration and corresponds to high degradation as displayed in Figure 8. Furthermore, the back contact module shows less flow: as both front and back connections cause significant degradations, this reveals that the leakage current through the back contact is most harmful than the front contact, and the power loss needs less transferred charges [38]. The frame contact module shows the smallest leakage current which is related to a small degradation in the first test. These results could give a correlation between power loss and the leakage current flowing under high voltage during PID test.

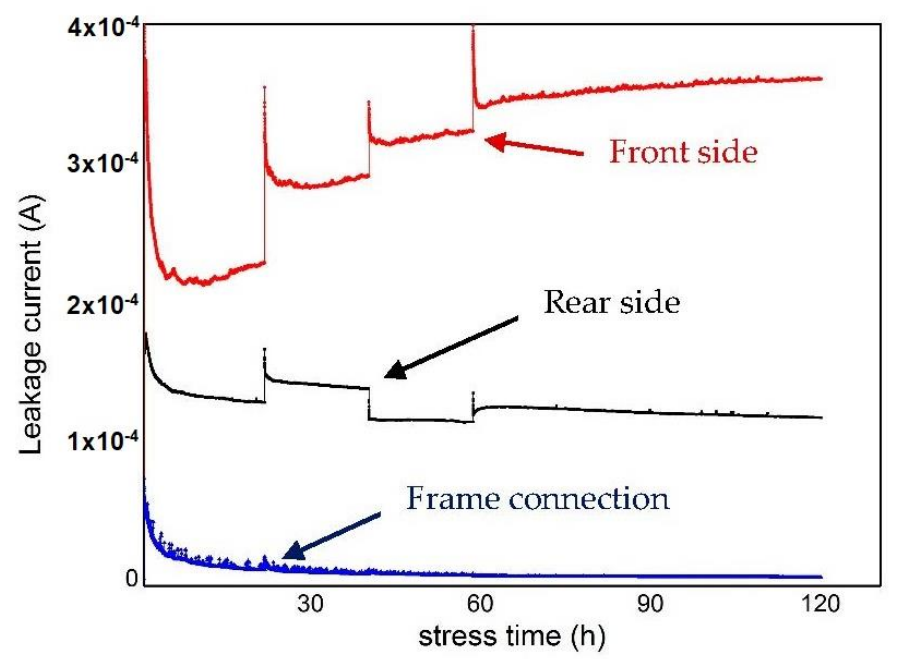

Figure 11. Leakage currents in three conditions under negative voltage: rear side, front side, and frame connection.

When the relative humidity is high, the wet surfaces of the modules become electrically conductive and thus a consistent leakage current can flow from the active solar cells to the grounded frame through the front and the back contact surfaces. This flow is facilitated by the low resistivity of the contacts which depends on the encapsulation material used in modules: as well known, the use of soda-lime 
glass in PV modules' technologies leads that sodium ions located at the front glass surface decrease their resistivity, and drive to significant leakage current to flow through this path. It is considered as a dominant path of leakage current, when a high voltage is applied. On the other hand, the back surface has more resistivity compared to the front glass explained by the small amount of $\mathrm{Na}$. This can reveal for less leakage current to flow as obtained after measurements.

The obtained results after the PID test can be correlated with the magnitude of leakage current generated by bias in damp-heat conditions, and flowing between the ground and the active cells: it reveals that the more the PID degradation occurs on PV modules, the more leakage current to flow in the modules. This correlation can be considered as an indicator of PID effect on PV modules. Figure 12 depicts the results of leakage current flowing in the three modules after applying the positive bias. However, the analysis of leakage current during recovery process shows that similar magnitude of current to flow in the opposite direction, as during PID stress, where the leakage current flowing through the front side has decreased more than a half at the end of the test.

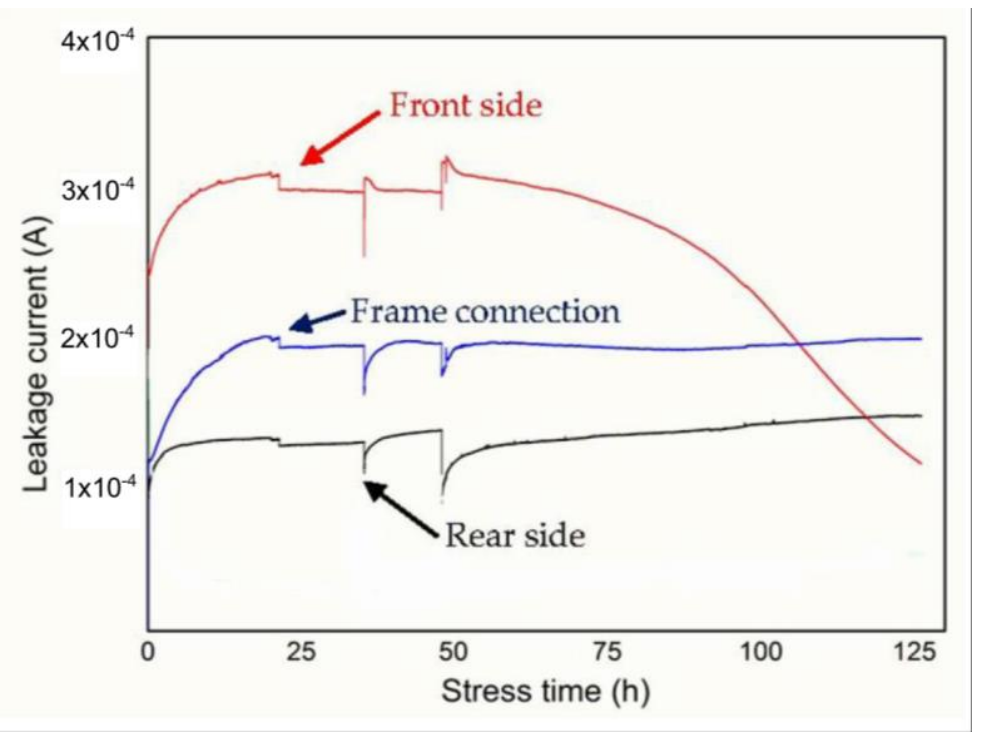

Figure 12. Leakage current progress during tests with high positive voltage of $1000 \mathrm{~V}$.

Summarizing, a correlation exists, in case of negative voltage, between the leakage current and the power loss, but a general relationship between the leakage current and the performance degradation cannot be defined.

\section{Conclusions}

In this work, PID accelerated tests have been performed on a group of commercial CIGS modules inside a damp-heat climatic chamber, comparing the effects due to PID with traditional crystalline technologies. The degradation behaviour of modules at the end of the test has been investigated and the modules have suffered from PID only under negative bias. The affected modules have exhibited performance degradation, mainly the maximum power and fill factor as well as other electrical parameters. However, the degraded modules showed no visible defects, while EL images have proved the degradation process at the cell level: a remarkable decrease in shunt resistances and an increase in series resistances have been detected. It is generally confirmed that the tested modules show to degrade highly by applying the high voltage on the back or front surface. The main cause of this mechanism can be associated with the migration and accumulation of $\mathrm{Na}$ ions on the active solar cells of the affected modules. For both negative bias and positive bias, a high level of leakage current flows between module surfaces and the active solar cells by applying high voltage. The measured leakage current can be suggested as a rate of the modules susceptibility to PID stress. Positive voltage has no 
PID effect on the tested modules, which can reveal that a correlation between the measured leakage current in case of negative bias and the power degradation can be confirmed. Applying the bias to the front side has been driven to partially recover the degraded performance of PID affected modules.

Future work will extend the measurement campaign to the modules of other manufacturers. Measurements will be performed on new modules in laboratory and field environments, to better quantify the performance variation over longer durations, and as a function of weather conditions. This work will permit us to quantify the new progress performed by the manufacturers developing the new typology of materials and coatings to reduce the flow of leakage currents, especially in the front glass and in the backsheet of the PV modules.

Author Contributions: The authors equally shared the work. S.B. carried out the experiments. All authors have read and agreed to the published version of the manuscript.

Funding: This research received no external funding.

Conflicts of Interest: The authors declare no conflict of interest.

\section{References}

1. Martinez-Moreno, F.; Figueiredo, G.; Lorenzo, E. In-the-field PID related experiences. Sol. Energy Mater. Sol. Cells 2018, 174, 485-493. [CrossRef]

2. Xiong, Z.; Walsh, T.M.; Aberle, A.G. PV module durability testing under high voltage biased damp heat conditions. Energy Procedia 2011, 8, 384-389. [CrossRef]

3. Hacke, P.; Smith, R.; Terwilliger, K.; Glick, S.; Jordan, D.; Johnston, S.; Kemp, M.; Kurtz, S. Acceleration factor determination for potential-induced degradation in crystalline silicon PV modules. In Proceedings of the 2013 IEEE International Reliability Physics Symposium (IRPS), Anaheim, CA, USA, 14-18 April 2013.

4. Nagel, H.; Metz, A.; Wangemann, K. Crystalline Si solar cells and modules featuring excellent stability against potential-induced degradation. In Proceedings of the 26th European Photovoltaic Solar Energy Conference and Exhibition, Hamburg, Germany, 5-9 September 2011.

5. Islam, M.A.; Hasanuzzaman, M.; Rahim, N.A. A comparative investigation on in-situ and laboratory standard test of the potential induced degradation of crystalline silicon photovoltaic modules. Renew. Energy 2018, 127, 102-113. [CrossRef]

6. Lechner, P.; Sanchez, D.; Geyer, D.; Mohring, H.-D. Estimation of time to PID-failure by characterisation of module leakage currents. In Proceedings of the 27th European Photovoltaic Solar Energy Conference and Exhibition, Frankfurt, Germany, 24-28 September 2012.

7. Oh, J.; Bowden, S.; TamizhMani, G. Potential-induced degradation (PID): Incomplete recovery of shunt resistance and quantum efficiency losses. IEEE J. Photovolt. 2015, 5, 1540-1548. [CrossRef]

8. Goranti, S.; TamizhMani, G. Potential induced degradation (PID) study on accelerated stress tested PV modules. In Proceedings of the 2012 38th IEEE Photovoltaic Specialists Conference, Austin, TX, USA, 3-8 June 2012.

9. Hara, K.; Ichinose, H.; Murakami, T.N.; Masuda, A. Crystalline Si photovoltaic modules based on TiO 2-coated cover glass against potential-induced degradation. RSC Adv. 2014, 4, 44291-44295. [CrossRef]

10. Pingel, S.; Frank, O.; Winkler, M.; Daryan, S.; Geipel, T.; Hoehne, H.; Berghold, J. Potential induced degradation of solar cells and panels. In Proceedings of the 2010 35th IEEE Photovoltaic Specialists Conference (PVSC), Honolulu, HI, USA, 20-25 June 2010.

11. Lausch, D.; Naumann, V.; Breitenstein, O.; Bauer, J.; Graff, A.; Bagdahn, J.; Hagendorf, C. Potential-induced degradation (PID): Introduction of a novel test approach and explanation of increased depletion region recombination. IEEE J. Photovolt. 2014, 4, 834-840. [CrossRef]

12. Naumann, V.; Lausch, D.; Graff, A.; Werner, M.; Swatek, S.; Bauer, J.; Hähnel, A.; Breitenstein, O.; Großer, S.; Bagdahn, J.; et al. The role of stacking faults for the formation of shunts during potential-induced degradation of crystalline Si solar cells. Phys. Status Solidi RRL Rapid Res. Lett. 2013, 7, 315-318. [CrossRef]

13. Luo, W.; Khoo, Y.S.; Hacke, P.; Naumann, V.; Lausch, D.; Harvey, S.P.; Singh, J.P.; Chai, J.; Wang, Y.; Aberleae, A.G.; et al. Potential-induced degradation in photovoltaic modules: A critical review. Energy Environ. Sci. 2017, 10, 43-68. [CrossRef] 
14. Fjällström, V. Potential-Induced Degradation of CuIn1-x Gax Se2Thin Film Solar Cells. IEEE J. Photovolt. 2013, 3, 1090-1094. [CrossRef]

15. Hacke, P.; Smith, R.; Terwilliger, K.; Glick, S.; Pankow, J.; Kloss, M.; Kurtz, S. System voltage potential-induced degradation mechanisms in PV modules and methods for test. In Proceedings of the 2011 37th IEEE Photovoltaic Specialists Conference (PVSC), Seattle, WA, USA, 19-24 June 2011.

16. Voswinckel, S.; Wesselak, V.; Fokuhl, E.; Schmidt, C.; Watzlawik, K. Dos and don'ts of leakage current measurement. In Proceedings of the 31th European Solar Energy Conference and Exhibition, Hamburg, Germany, 14-18 September 2015.

17. Manz, P.; Wesselak, V.; Voswinckel, S.; Trautmann, B.; Fokuhl, E.; Schmidt, C. Leakage current pathways and magnitudes in correlation to PID of CIGS thin film modules. In Proceedings of the 29th European Solar Energy Conference and Exhibition, Amsterdam, The Netherlands, 22-26 September 2014.

18. Colli, A. The role of sodium in photovoltaic devices under high voltage stress: A holistic approach to understand unsolved aspects. Renew. Energy 2013, 60, 162-168. [CrossRef]

19. Schroeder, D.J.; Rockett, A.A. Electronic effects of sodium in epitaxial CuIn ${ }_{1-x} \mathrm{Ga}_{\mathrm{x}} \mathrm{Se}_{2}$. J. Appl. Phys. 1997, 82, 4982-4985. [CrossRef]

20. Dhere, N.G.; Shiradkar, S.N.; Schneller, E. Evolution of Leakage Current Paths in MC-Si PV Modules From Leading Manufacturers Undergoing High-Voltage Bias Testing. IEEE J. Photovolt. 2014, 4, 654-658. [CrossRef]

21. Naumanna, V.; Lauscha, D.; Hähnelb, A.; Bauerb, J.; Breitensteinb, O.; Graff, A.; Werner, M.; Swatek, S.; Großer, S.; Bagdahn, J.; et al. Explanation of potential-induced degradation of the shunting type by $\mathrm{Na}$ decoration of stacking faults in Si solar cells. Sol. Energy Mater. Sol. Cells 2014, 120, 383-389. [CrossRef]

22. Yamaguchi, S.; Jonai, S.; Hara, K.; Komaki, H.; Shimizu-Kamikawa, Y.; Shibata, H.; Niki, S.; Kawakami, Y.; Masuda, A. Potential-induced degradation of $\mathrm{Cu}$ (In, Ga) Se2 photovoltaic modules. Jpn. J. Appl. Phys. 2015, 54, 08KC13. [CrossRef]

23. Spertino, F.; Sumaili, J.; Andrei, H.; Chicco, G. PV Module Parameter Characterization from the Transient Charge of an External Capacitor. IEEE J. Photovolt. 2013, 3, 1325-1333. [CrossRef]

24. Carullo, A.; Castellana, A.; Vallan, A.; Ciocia, A.; Spertino, F. Uncertainty issues in the experimental assessment of degradation rate of power ratings in photovoltaic modules. Measurement 2017, 111, 432-440. [CrossRef]

25. Spertino, F.; Ahmad, J.; Ciocia, A.; di Leo, P.; Murtaza, A.F.; Chiaberge, M. Capacitor charging method for I-V curve tracer and MPPT in photovoltaic systems. Sol. Energy 2015, 119, 461-473. [CrossRef]

26. Ciocia, A.; Carullo, A.; di Leo, P.; Malgaroli, G.; Spertino, F. Realization and Use of an IR Camera for Laboratory and On-field Electroluminescence Inspections of Silicon Photovoltaic Modules. In Proceedings of the 2019 IEEE 46th Photovoltaic Specialist Conference (PVSC), Chicago, IL, USA, 16-21 July 2019. in press.

27. Fuyuki, T.; Kondo, H.; Yamazaki, T.; Takahashi, Y.; Uraoka, Y. Photographic surveying of minority carrier diffusion length in polycrystalline silicon solar cells by electroluminescence. Appl. Phys. Lett. 2005, 86. [CrossRef]

28. Lavrenko, T.; Runai, F.R.; Wang, Y.; Teukam, M.; Walter, T.; Hahn, T.; Pistor, P. Advanced luminescence imaging of cigs solar cells. In Proceedings of the 27th European Photovoltaic Solar Energy Conference and Exhibition, Frankfurt, Germany, 24-28 September 2012.

29. Spertino, F.; Ahmad, J.; Ciocia, A.; di Leo, P. Techniques and Experimental Results for Performance Analysis of Photovoltaic Modules Installed in Buildings. Energy Procedia 2017, 111, 944-953. [CrossRef]

30. IEC 60904-9. Photovoltaic Devices - Part 9: Solar Simulator Performance Requirements; International Organization for Standardization, ISO Central Secretariat: Geneva, Switzerland, 2007.

31. BERGER Lichttechnik, Datasheet of Solar Simulation Device "SS8". Available online: https://www. bergerlichttechnik.de/wp-content/uploads/2018/07/berger_PSS_8_rev417.pdf (accessed on 6 November 2019).

32. Lee, D.-W.; Cho, W.-J.; Song, J.-K.; Kwon, O.-Y.; Lee, W.-H.; Park, C.-K.; Park, K.-E.; Lee, H.; Kim, Y.-N. Failure analysis of $\mathrm{Cu}$ (In, Ga) Se2 photovoltaic modules: Degradation mechanism of $\mathrm{Cu}$ (In, Ga) Se2 solar cells under harsh environmental conditions. Prog. Photovolt. Res. Appl. 2014, 23, 829-837. [CrossRef]

33. Tosun, B.S.; Feist, R.K.; Gunawan, A.; Mkhoyan, K.A.; Campbell, S.A.; Aydil, E.S. Improving the damp-heat stability of copper indium gallium diselenide solar cells with a semicrystalline tin dioxide overlayer. Sol. Energy Mater. Sol. Cells 2012, 101, 270-276. [CrossRef] 
34. Deline, C.; Stokes, A.; Silverman, T.J.; Rummel, S.; Jordan, D.; Kurtz, S. Electrical bias as an alternate method for reproducible measurement of copper indium gallium diselenide (CIGS) photovoltaic modules. In Reliability of Photovoltaic Cells, Modules, Components, and Systems V; International Society for Optics and Photonics: San Diego, CA, USA, 2012; Volume 8472.

35. Kobayashi, T.; Yamaguchi, H.; Nakada, T. Effects of combined heat and light soaking on device performance of $\mathrm{Cu}(\mathrm{In}, \mathrm{Ga}) \mathrm{Se} 2$ solar cells with ZnS (O, OH) buffer layer. Prog. Photovolt. Res. Appl. 2013, 22, 115-121. [CrossRef]

36. Dunn, L.; Gostein, M. Light soaking measurements of commercially available CIGS PV modules. In Proceedings of the 2012 38th IEEE Photovoltaic Specialists Conference (PVSC), Austin, TX, USA, 3-8 June 2012.

37. Helbig, A.; Kirchartz, T.; Schaeffler, R.; Werner, J.H.; Rau, U. Quantitative electroluminescence analysis of resistive losses in $\mathrm{Cu}$ (In, Ga) Se2 thin-film modules. Sol. Energy Mater. Sol. Cells 2010, 94, 979-984. [CrossRef]

38. Voswinckel, S.; Wesselak, V.; Münter, S.; Gerstenberg, L. Correlation of Leakage Current Pathways and Potential Induced Degradation of CIGS Thin Film Solar Modules. In Proceedings of the ISES Solar World Conference 2017 and the IEA SHC Solar Heating and Cooling Conference for Buildings and Industry 2017, Abu Dhabi, UAE, 29 October-2 November 2017.

(C) 2020 by the authors. Licensee MDPI, Basel, Switzerland. This article is an open access article distributed under the terms and conditions of the Creative Commons Attribution (CC BY) license (http://creativecommons.org/licenses/by/4.0/). 